\title{
Systematized Nomenclature of Medicine Clinical Terms
}

National Cancer Institute

\section{Source}

National Cancer Institute. Systematized Nomenclature of Medicine Clinical Terms. NCI

Thesaurus. Code C49469.

Published by the College of American Pathologists, the Systematized Nomenclature of Medicine Clinical Terms is a combination of content of SNOMED Reference Terminology and READ codes. 